\title{
Phenotypic evaluation and genetic dissection of resistance to Phytophthora sojae in the Chinese soybean mini core collection
}

Jing Huang ${ }^{1}, \mathrm{Na} \mathrm{Guo}{ }^{1}$, Yinghui Li ${ }^{2}$, Jutao Sun ${ }^{1}$, Guanjun Hu${ }^{1}$, Haipeng Zhang ${ }^{1}$, Yanfei Li ${ }^{2}$, Xing Zhang ${ }^{1}$, Jinming Zhao ${ }^{1}$, Han Xing ${ }^{1 *}$ and Lijuan Qiu ${ }^{2^{*}}$

\begin{abstract}
Background: Phytophthora root and stem rot (PRR) caused by Phytophthora sojae is one of the most serious diseases affecting soybean (Glycine max (L.) Merr.) production all over the world. The most economical and environmentally-friendly way to control the disease is the exploration and utilization of resistant varieties.

Results: We screened a soybean mini core collection composed of 224 germplasm accessions for resistance against eleven P. sojae isolates. Soybean accessions from the Southern and Huanghuai regions, especially the Hubei, Jiangsu, Sichuan and Fujian provinces, had the most varied and broadest spectrum of resistance. Based on gene postulation, Rps1b, Rps1c, Rps4, Rps7 and novel resistance genes were identified in resistant accessions. Consequently, association mapping of resistance to each isolate was performed with 1,645 single nucleotide polymorphism (SNP) markers. A total of 14 marker-trait associations for Phytophthora resistance were identified. Among them, four were located in known PRR resistance loci intervals, five were located in other disease resistance quantitative trait locus (QTL) regions, and five associations unmasked novel loci for PRR resistance. In addition, we also identified candidate genes related to resistance.

Conclusion: This is the first $P$. sojae resistance evaluation conducted using the Chinese soybean mini core collection, which is a representative sample of Chinese soybean cultivars. The resistance reaction analyses provided an excellent database of resistant resources and genetic variations for future breeding programs. The SNP markers associated with resistance will facilitate marker-assisted selection (MAS) in breeding programs for resistance to PRR, and the candidate genes may be useful for exploring the mechanism underlying $P$. sojae resistance.
\end{abstract}

Keywords: Soybean mini core collection, Phytophthora sojae, Resistance evaluation, Association mapping, Genetic diversity

\footnotetext{
* Correspondence: hanx@njau.edu.cn; qiulijuan@caas.cn

${ }^{1}$ National Center for Soybean Improvement/National Key laboratory of Crop

Genetics and Germplasm enhancement, Key laboratory of Biology and

Genetics and Breeding for Soybean, Ministry of Agriculture, Nanjing

Agricultural University, Nanjing 210095, People's Republic of China

${ }^{2}$ The National Key Facility for Crop Gene Resources and Genetic

Improvement (NFCRI)/Key Lab of Germplasm Utilization (MOA), Institute of

Crop Science, Chinese Academy of Agricultural Sciences, 100081 Beijing,

People's Republic of China
}

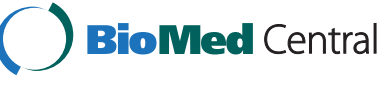

(c) 2016 The Author(s). Open Access This article is distributed under the terms of the Creative Commons Attribution 4.0 International License (http://creativecommons.org/licenses/by/4.0/), which permits unrestricted use, distribution, and reproduction in any medium, provided you give appropriate credit to the original author(s) and the source, provide a link to the Creative Commons license, and indicate if changes were made. The Creative Commons Public Domain Dedication waiver (http://creativecommons.org/publicdomain/zero/1.0/) applies to the data made available in this article, unless otherwise stated. 


\section{Background}

Phytophthora root and stem rot (PRR) caused by the oomycete pathogen Phytophthora sojae Kaufmann \& Gerdemann brings about extensive economic losses worldwide [1]. The pathogen infects soybean throughout the growing season, resulting in seedling damping-off and root and stem rotting of mature plants. $P$ sojae isolates are classified into pathotypes based on the reactions of soybean differentials carrying resistance genes, and more than two hundred pathotypes of $P$. sojae have been identified worldwide to date [2, 3]. In China, an aboriginal $P$. sojae isolate was first found in 1989 in Heilongjiang province $[4,5]$. Since then, the emergence of new races and their virulence diversity have been reported continuously in other major soybean production areas around the Huanghuai valley and in southern China [6], implying that PRR is a potential threat to Chinese soybean production.

Deployment of Rps (resistance to P. sojae) genes in soybean cultivars has been an effective method of controlling PRR [7] because Rps genes mediate complete or race-specific resistance. To date, at least twenty $R p s$ genes that protect against $P$. sojae infection have been identified in soybean [8-14]. The efficacies of these Rps genes are dependent on the presence of corresponding avirulence $(A v r)$ genes in the pathogen. The Rps genes recognize $A v r$ genes secreted from $P$. sojae in a gene-forgene model, thus activating the plant resistant response $[15,16]$. Under the theory of pathogen-host coevolution [17], P. sojae is under strong selection pressure, and new pathotypes are constantly evolving. Therefore, the Rps genes is easily overcome by changes in the virulence of P. sojae [16].

Normally, a single Rps gene is effective for only 8 to 15 years [18]. The first Rps gene Rps $1 \mathrm{k}$ was identified in 1957 [8]; to date, no single Rps gene has been found to confer resistance to all $P$. sojae isolates, and new virulent pathotypes of $P$. sojae have continued to emerge. Mining of novel resistance genes has thus become an urgent priority in soybean resistance breeding. Many surveys on resistant germplasm characterization and resistance gene discovery in the Chinese soybean have been performed [19-22]. In these surveys, soybean germplasm accessions were randomly selected and concentrated in certain regions, such as central China [19], southern China [20] and the Huanghuai region [21, 22].

Chinese soybean germplasm resources are very vast, making it difficult to thoroughly evaluate Phytophthora resistance; so far, no systematic screening of countrywide soybean germplasm for resistance has been carried out. The soybean mini core collection is a preferred choice for efficient exploration of variations in genetic resources because it represents $1 \%$ of the entire GeneBank collection but $94.5 \%$ of the soybean phenotypic diversity and $63.5 \%$ of the genetic diversity of the collection [23]. The soybean mini core collection has been used to evaluate desirable traits, such as protein subunit variations and seed quality traits, and some of the mini core collection accessions have been used to identify disease phenotype, such as soybean cyst nematode (SCN) and soybean mosaic virus (SMV) [24]. Recently, variants partial resistant to $P$. sojae in the mini core collection were also characterized [25].

Association mapping is a method used to identify markers associated with a particular trait by using linkage disequilibrium (LD) between alleles within natural populations [26], with no need for developing biparental populations [27]. Recently, association mapping has been used to identify marker-trait associations in higher plants [28, 29], including various disease resistance associations in soybean, such as sclerotinia stem rot (SSR) resistance $[30,31]$ and sudden death syndrome (SDS) resistance [32]. The mini core collection, most of which consists of local landraces with alleles left behind during the processes of domestication and positive selection [24], may be an ideal population for association mapping analysis.

Here, we report phenotypic and genotypic screening of the Chinese soybean mini core collection for resistance to eleven $P$. sojae isolates with varying virulence. Our aim is to investigate the distribution of Phytophthora resistant germplasm and provide a new resistance gene pool for future breeding programs. An association analysis was developed to identify markers associated with Phytophthora resistance in the mini core collection, and the results will be useful for genomic identification of loci conferring resistance to $P$. sojae and for exploration of the genetic basis of resistance.

\section{Methods \\ Plant materials}

The soybean mini core collection is a set of 248 accessions chosen from 23,587 germplasm accessions conserved in the Chinese National Soybean GeneBank (CNSGB), which effectively maintains the genetic diversity of soybean in China. The accessions were provided by Professor Lijuan Qiu of the Chinese Academy of Agriculture Sciences. Excluding those without SNP marker data, 224 accessions from the mini core collection were used in this study. The collection consists of 196 landraces and 28 modern cultivars originating from 26 provinces and spread across four ecological regions representing four major soybean planting areas as follows: the North region (NR), the Northeast region (NER), the Huanghuai region (HHR) and the South region (SR) (Additional file 1 ). 
A set of 13 differential cultivars, each possessing a single Rps gene, and one susceptible cultivar without any known $R p s$ genes were used to confirm the pathotypes of the P. sojae isolates. These cultivars were Harlon (Rps1a), Harosoy13XX (Rps1b), Williams79 (Rps1c), PI103091 (Rps1d), Williams82 (Rps1k), L76-1988 (Rps2), Chapman (Rps3a), PRX146-36 (Rps3b), PRX145-48 (Rps3c), L85-2352 (Rps4), L85-3059 (Rps5), Harosoy62XX (Rps6), Harosoy (Rps7) and Williams (susceptible). The seeds were stored in our laboratory.

\section{Pathogen isolate virulence}

The 11 P. sojae isolates (P6497, HLJ08-17, P7063, AH, H15, HeN08-35, PNJ1, Pmg, Pm28, Pm31 and JS08-12) were obtained from Professor Yuanchao Wang of Nanjing Agricultural University. The isolates were maintained on V8 juice agar slant at $15{ }^{\circ} \mathrm{C}$ and transferred to V8 juice agar plate medium at $25^{\circ} \mathrm{C}$ for 7 days prior to inoculation. All isolates were tested for virulence against the above differential cultivars using the hypocotyl inoculation technique with mycelium [33]. The isolate virulence formulas and areas of origin are listed in Table 1.

\section{Plant inoculation and disease assessment}

The resistance of the accessions from the soybean mini core collection was evaluated using the hypocotyl inoculation technique with mycelium, which is the preferred method for evaluating soybean resistance to $P$. sojae mediated by Rps genes [2]. All screening experiments were conducted at Nanjing Agricultural University in Nanjing, China. Ten seeds of each germplasm accession were planted in a plastic pot filled with vermiculite. Seedling were grown in a greenhouse at $25^{\circ} \mathrm{C}$ with a 14-h photoperiod and watered once daily. When its cotyledons fully opened (approximately seven days after planting), the seedlings were prepared for inoculation. An incision (approximately $1 \mathrm{~cm}$ in length) was made in the

Table 1 Virulence formula of 11 isolates of Phytophthora sojae

\begin{tabular}{|c|c|c|}
\hline Isolates of P. sojae & Virulence formula ${ }^{a}$ & Origin \\
\hline P6497 & $1 b, 7$ & America \\
\hline HLJ08-17 & $2,4,5,7$ & Heilongjiang, China \\
\hline P7063 & $1 a, 1 d, 3 a, 6,7$ & America \\
\hline $\mathrm{AH}$ & $2,3 a, 3 b, 4,5$ & Anhui, China, \\
\hline $\mathrm{H} 15$ & $1 b, 3 b, 3 c, 5,6,7$ & Heilongjiang, China \\
\hline HeN08-35 & $3 a, 3 c, 4,5,6,7$ & Henan, China \\
\hline PNJ1 & $1 d, 2,3 b, 3 c, 4,5,7$ & Jiangsu, China \\
\hline Pmg & $1 b, 1 d, 2,3 a, 3 b, 4,5,6,7$ & America \\
\hline $\operatorname{Pm} 28$ & $1 a, 1 b, 1 c, 1 d, 1$ k,2,3a,3b,3c,5,6,7 & America \\
\hline Pm31 & $1 a, 1 b, 1 c, 1 d, 1$ k,2,3b,3c,4,5,6,7 & America \\
\hline JS08-12 & $1 a, 1 b, 1 c, 1 d, 1 k, 2,3 a, 3 b, 3 c, 4,5,6,7$ & Jiangsu, China \\
\hline
\end{tabular}

${ }^{a}$ virulence formula shows the resistance gene(s) defeated by an isolate of $P$. sojae hypocotyl below the cotyledonary node, and a piece of agar (approximately $3 \mathrm{~mm}$ square) with mycelium was inoculated into the wound. The inoculated seedlings were placed in a mist room $(90 \%$ relative humidity) at $25{ }^{\circ} \mathrm{C}$ without light for $10 \mathrm{~h}$ and then returned to the greenhouse. The experiment was repeated three times for each isolate to confirm the reactions between $P$. sojae and the seedlings. For each time of inoculation, the differential cultivars were included to verify the success of the inoculation.

Five days after inoculation, accessions were evaluated based on the percentage of survival plants from all replications. Susceptible plants suffered a collapse of the hypocotyl and died, whereas resistant plants developed a hypersensitive reaction (slight necrotic lesions around the wounds). An accession was considered susceptible (S) if less than $30 \%$ of the seedlings survived and was considered resistant (R) if more than $70 \%$ of the seedlings survived. Seedlings survival percentages ranging from $30 \%$ to $70 \%$ were considered intermediate (I) reactions. Intermediate reactions have been broadly classified as resistant reactions according to previous reports [20].

\section{SNP data}

The mini core collection was genotyped with 1,645 SNP markers provided by Professor Lijuan Qiu (listed in Additional file 2); among them, 577 SNPs had already been reported [34]. Minor allele frequency and heterozygosity of markers were assessed using PowerMarker 3.25 software [35].

\section{Linkage disequilibrium}

Pairs of SNPs on the same chromosome were identified as linked SNPs, while those on different chromosomes were identified as unlinked SNPs. The correlation coefficient $r^{2}$ was used to estimate the degree of linkage disequilibrium (LD) between each pair of SNPs using TASSEL 5 software [36]. LD decay was evaluated using a nonlinear regression of expected $r^{2}$, as described with $\mathrm{E}$ $\left(r^{2}\right)=1 /\left(1+4 N_{\mathrm{e}} c\right)$ [37], where $N_{\mathrm{e}}$ is the effective population size, and $c$ is the recombination rate in Morgan units. We assumed that the soybean genome (Williams 82) and the linkage map had equal sizes (approximately $1.1 \mathrm{~GB}=2500 \mathrm{cM}$ ) and that $1 \mathrm{cM}=440 \mathrm{~Kb}$ between the recombination rates and physical distances. In this way, the physical position of SNP markers was converted to the recombination rate $c$. The $N_{\mathrm{e}}$ value was estimated using R software (http://www.R-project.org), according to the linear relationship between $c$ and $r^{2}$. Based on the method developed by Mather [38], the $r^{2}$ threshold value fell on the 95th percentile of the unlinked SNPs $r^{2}$ value. 


\section{Population structure and kinship}

STRUCTURE 2.2 software [39] was used to estimate population structure. With an admixture model and an independent allele frequency model, the number of populations (K) was set from 1 to 15 with 5 replications for each $\mathrm{K}$, with the length of the burn-in period set to 10,000 and the number of Monte Carlo Markov Chain (MCMC) replications set to 100,000 . K value estimation was determined by the log probability of the data LnP (D) and delta K. Previous studies indicated that there were two or three distinct subgroups in the mini core collection depending on the markers used in the tests $[25,40]$. Based on the Q-matrix obtained from the membership probability of each variety, the mini core collection was divided into such subgroups [41].

The kinship matrix [42] was estimated as the genotype similarity between the different pairs of SNPs using TASSEL 5 software [36].

\section{Association mapping}

Association analysis was performed using TASSEL 5 software [36]. Three different models were used to test associations between SNP markers and resistance. The first model was the Naive model, which contained only the SNPs being tested. The second model was a general linear model (GLM) with the Q matrix as a covariate. The third model was a mixed linear model (MLM), where the Q matrix and the relative kinship matrix were included as covariates. The significant association threshold was set to a $P$-value $<10^{-3}\left(-\log _{10} P>3.00\right)$.

\section{Candidate gene prediction and annotation}

Candidate gene positions and functional annotations were retrieved from the Phytozome database (http:// www.phytozome.org/) and the Soybase database (http:// www.soybase.org/).

\section{Results}

Resistance reaction to $P$. sojae isolates in the soybean mini core collection

A total of $11 P$. sojae isolates were used to evaluate the resistance of 224 accessions of the Chinese soybean (G. $\max$ ) mini core collection. The pathotype complexity of the isolates ranged from 2 to 12 (Table 1). The isolates had the most virulence interactions with Rps7 (91\%), followed by Rps6 (82\%) and Rps5 (72\%), and the least virulence interactions with Rps1c (27\%) and Rps1a (36 \%) (Additional file 3).

The soybean mini core collection showed varying resistance reactions to the diverse virulence of the isolates. As shown in Fig. 1 and Table 2, more than half of the soybean collection had susceptible reactions to each isolate, which indicates that the soybean in China is extremely susceptible. The largest proportion of soybean germplasm accessions showed up to $40.2 \%$ resistance to the $\mathrm{AH}$ isolate. More than half of these resistant accessions came from the Sichuan (13), Hubei (11), Jiangsu (8), Fujian (7), Shandong (6), and Heilongjiang (6) provinces, which are located in South and Huanghuai regions of China. The percentages of accessions with resistance to the P7063 and HLJ08-17 isolates were $37.1 \%$ and $31.7 \%$, respectively, which ranked second and third. These resistant accessions were mainly from the Hubei (10/13), Jiangsu (9/11), Fujian (8/6), Sichuan (9/3), Shandong (6/5), Hebei (4/6) and Jiangxi (6/6) provinces, which are also located in the South and Huanghuai regions. The percentages of accessions resistant to the other isolates ranged from $22.3 \%$ to $16.5 \%$. Few

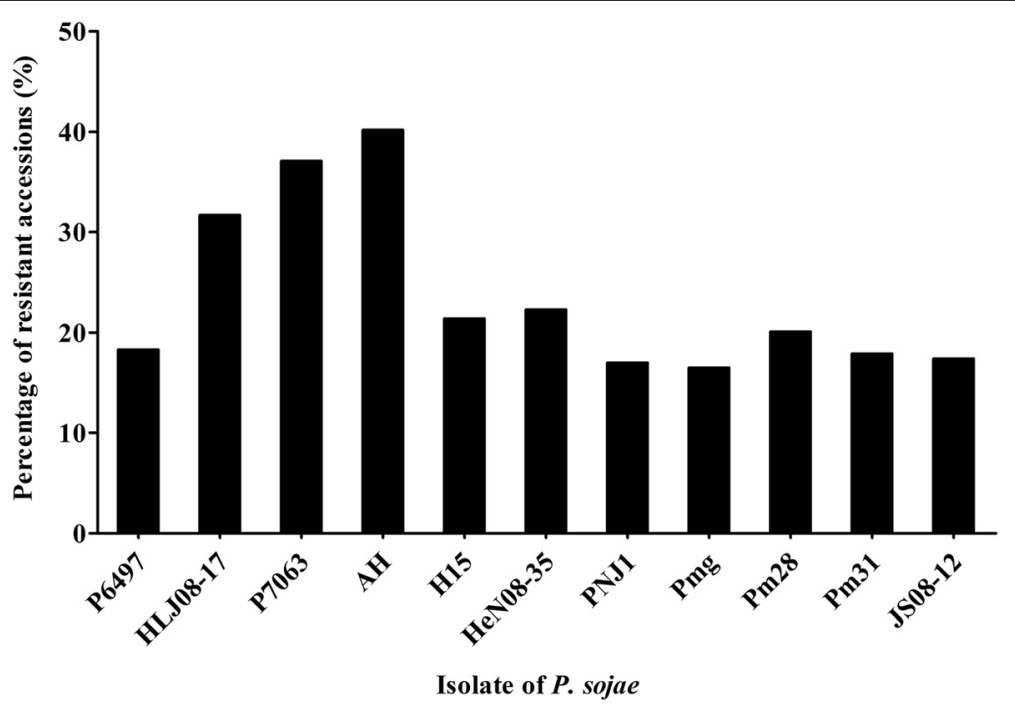

Fig. 1 The percentage of resistant accessions to 11 isolates of $P$. sojae 
Table 2 Geographic distribution of soybean germplasm with resistant to 11 isolates of $P$. sojae

\begin{tabular}{|c|c|c|c|c|c|c|c|c|c|c|c|}
\hline \multirow[t]{2}{*}{ Origin region } & \multicolumn{11}{|c|}{ Isolate of $P$. sojae } \\
\hline & P6497 & HLJ08-17 & P7063 & $\mathrm{AH}$ & $\mathrm{H} 15$ & HeN08-35 & PNJ1 & Pmg & Pm28 & Pm31 & JS08-12 \\
\hline Jiangsu & 6 & 11 & 9 & 8 & 6 & 8 & 6 & 6 & 4 & 4 & 7 \\
\hline Hubei & 8 & 13 & 10 & 11 & 4 & 9 & 6 & 6 & 7 & 5 & 2 \\
\hline Sichuan & 3 & 3 & 9 & 13 & 4 & 3 & 6 & 3 & 4 & 5 & 2 \\
\hline Fujian & 5 & 6 & 8 & 7 & 5 & 4 & 5 & 3 & 1 & 4 & 3 \\
\hline Jiangxi & 1 & 6 & 6 & 2 & 4 & 6 & 1 & 1 & 1 & 3 & 2 \\
\hline Heilongjiang & 1 & 1 & 1 & 6 & 3 & 1 & 1 & 1 & 4 & 7 & 5 \\
\hline Shandong & 2 & 5 & 6 & 6 & 4 & 3 & 2 & 0 & 1 & 0 & 1 \\
\hline Hebei & 1 & 6 & 4 & 2 & 2 & 3 & 1 & 2 & 4 & 1 & 3 \\
\hline Hunan & 3 & 1 & 5 & 5 & 4 & 2 & 1 & 2 & 1 & 1 & 1 \\
\hline Jilin & 2 & 2 & 2 & 4 & 2 & 1 & 2 & 1 & 3 & 2 & 3 \\
\hline Liaoning & 2 & 3 & 3 & 2 & 1 & 2 & 1 & 2 & 4 & 3 & 2 \\
\hline Shannxi & 1 & 2 & 4 & 4 & 1 & 2 & 1 & 2 & 1 & 2 & 0 \\
\hline Henan & 1 & 1 & 4 & 4 & 1 & 1 & 1 & 1 & 1 & 0 & 1 \\
\hline Guangdong & 2 & 3 & 3 & 3 & 3 & 1 & 1 & 1 & 3 & 1 & 0 \\
\hline Shanxi & 1 & 2 & 1 & 5 & 1 & 1 & 1 & 2 & 2 & 1 & 1 \\
\hline Guizhou & 1 & 0 & 1 & 3 & 0 & 0 & 1 & 2 & 1 & 1 & 0 \\
\hline Guangxi & 0 & 1 & 3 & 2 & 1 & 0 & 0 & 0 & 1 & 0 & 0 \\
\hline Anhui & 0 & 1 & 2 & 0 & 1 & 1 & 0 & 2 & 1 & 0 & 2 \\
\hline Zhejiang & 0 & 2 & 1 & 1 & 0 & 1 & 0 & 0 & 0 & 0 & 2 \\
\hline Hainan & 1 & 1 & 1 & 1 & 1 & 1 & 1 & 0 & 0 & 0 & 0 \\
\hline Xinjiang & 0 & 0 & 0 & 0 & 0 & 0 & 0 & 0 & 1 & 0 & 0 \\
\hline Gansu & 0 & 1 & 0 & 0 & 0 & 0 & 0 & 0 & 0 & 0 & 0 \\
\hline Inner mong & 0 & 0 & 0 & 1 & 0 & 0 & 0 & 0 & 0 & 0 & 0 \\
\hline Beijing & 0 & 0 & 0 & 0 & 0 & 0 & 0 & 0 & 0 & 0 & 1 \\
\hline Yunnan & 0 & 0 & 0 & 0 & 0 & 0 & 0 & 0 & 0 & 0 & 1 \\
\hline Ningxia & 0 & 0 & 0 & 0 & 0 & 0 & 0 & 0 & 0 & 0 & 0 \\
\hline North region & 5 & 6 & 6 & 13 & 6 & 4 & 4 & 4 & 11 & 12 & 10 \\
\hline Northeast region & 1 & 5 & 2 & 6 & 1 & 1 & 1 & 2 & 5 & 3 & 4 \\
\hline Huanghuai region & 10 & 19 & 24 & 21 & 12 & 14 & 10 & 9 & 8 & 5 & 7 \\
\hline South region & 25 & 41 & 51 & 50 & 29 & 31 & 23 & 22 & 21 & 20 & 18 \\
\hline
\end{tabular}

accessions (16.5\%) showed resistance to the Pmg isolate, and these came mainly from the Jiangsu (6), Hubei (6), Sichuan (3) and Fujian (3) provinces. In general, the germplasm from the provinces of Jiangsu, Hubei, Sichuan and Fujian in the South and Huanghuai regions of China contributed the top four resistant sources to each isolate (Table 2).

As shown in Fig. 2, soybean germplasm from the South region (SR) had the highest percentage of resistant accessions. More than $20 \%$ of accessions from the SR showed resistance to each isolate of $P$. sojae, and more than $40 \%$ of accessions showed resistance to the HeN08-35, HLJ08-17, P7063 and AH isolates. This was followed by the soybean germplasm from the Huanghuai region (HHR), for which more than $30 \%$ of accessions were resistant to the $\mathrm{AH}$ and Pm31 isolates. The germplasm from the Northeast region (NER) and the North region (NR) had lower percentages of resistant accessions. The most resistant accessions from the NR were resistant to the $\mathrm{AH}$, HLJ08-17 and Pm28 isolates, but all of them had percentages of resistant accessions less than $20 \%$. Notably, more than $20 \%$ of accessions from the SR and NER were resistant to the Pm28, Pm31 and JS0812 isolates, which were the most virulent isolates that we used. 


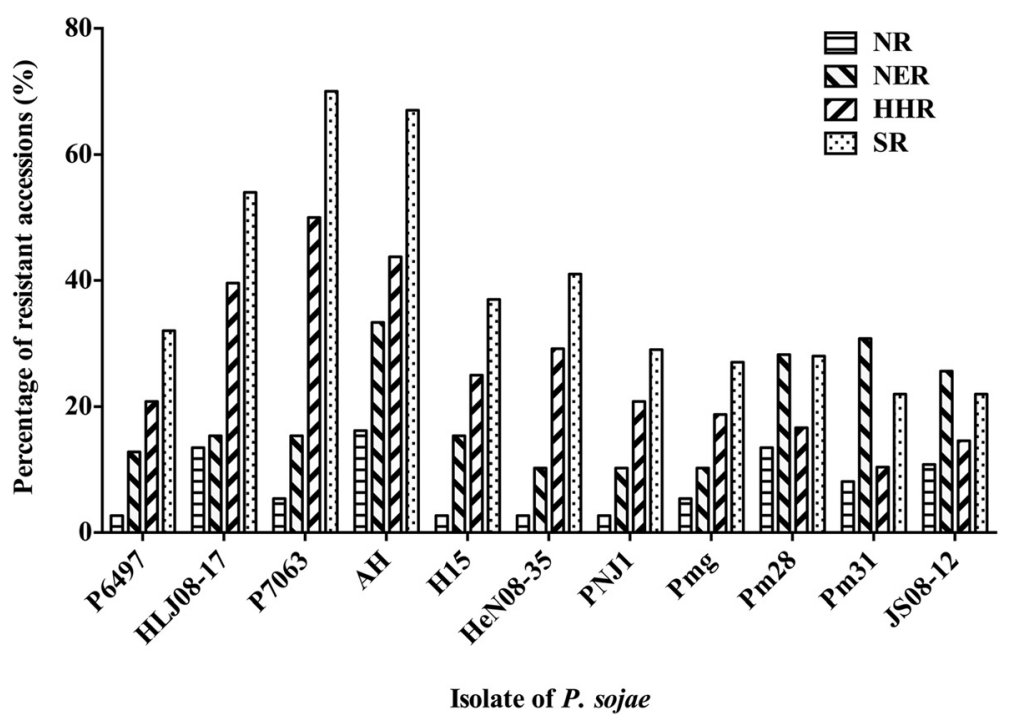

Fig. 2 The percentage of resistant accessions in different eco-regions to 11 isolates of $P$. sojae

Investigation of the distribution of multi-resistant soybean germplasm in China

There were 168 (75\%) soybean accessions resistant to 1-11 isolates (Fig. 3 and Table 3). Among them, sixtyfive $(29.0 \%)$ accessions were resistant to $1-2$ isolates, which were concentrated in the Sichuan (7), Shanxi (6), Hebei (6), Shandong (5), Jilin (5) and Liaoning (5) provinces. Fifty-six (25.0\%) accessions were resistant to 3-4 isolates; these accessions were distributed in the Jiangsu (8), Sichuan (7), Heilongjiang (5), Henan (4), Hunan (4) and Jiangxi (4) provinces. Thirty-nine (24.6 \%) accessions were resistant to 5-7 isolates. Most of them were concentrated in the Hubei (11) and Fujian (4), Sichuan (3) and Jiangsu (3) provinces. Eight accessions from the Jiangsu (2), Fujian (2), Hubei (1), Hebei (1), Liaoning (1) and Jiangxi (1) provinces were resistant to 8-11 isolates (Table 4); notably, the accession ZDD03776 from the Jiangsu province had the broadest spectrum of resistance, showing resistance to 11 isolates. Overall, most NR soybean accessions showed resistance to less than 4 isolates, and most NER accessions showed resistance to 1-5 isolates. SR and HHR accessions specifically from the Jiangsu, Hubei and Fujian provinces had the most variable and broad-spectrum resistance.

Postulation of resistance genes in the soybean mini core collection germplasm

There were 109 reaction types to $11 P$. sojae isolates in the soybean mini core collection (data not shown). By comparing the responses of the mini core collection and 13 differential cultivars, we postulated of gene(s) in the resistant soybean accessions (Table 5). Fifty-six

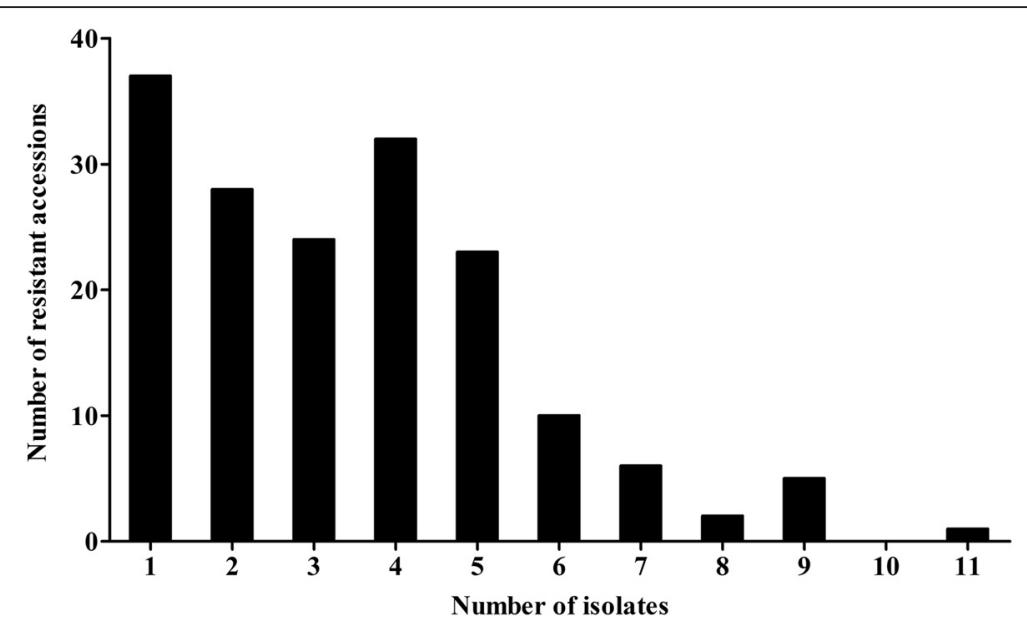

Fig. 3 The numbers of resistant accessions to multi-isolates of $P$. sojae 
Table 3 Geographic distribution of soybean germplasm with resistant to 1-11 P. sojae isolates

\begin{tabular}{|c|c|c|c|c|c|c|c|c|c|c|c|}
\hline \multirow[t]{2}{*}{ Origin region } & \multicolumn{11}{|c|}{ Number of isolates } \\
\hline & 1 & 2 & 3 & 4 & 5 & 6 & 7 & 8 & 9 & 10 & 11 \\
\hline Ningxia & - & - & - & - & - & - & - & - & - & - & - \\
\hline Gansu & 1 & - & - & - & - & - & - & - & - & - & - \\
\hline Yunnan & 1 & - & - & - & - & - & - & - & - & - & - \\
\hline Xinjiang & 1 & - & - & - & - & - & - & - & - & - & - \\
\hline Inner mong & 1 & - & - & - & - & - & - & - & - & - & - \\
\hline Beijing & 1 & - & - & - & - & - & - & - & - & - & - \\
\hline Guangxi & - & 1 & 2 & - & - & - & & - & - & - & - \\
\hline Guizhou & 2 & 1 & 2 & - & - & - & & - & - & - & - \\
\hline Zhejiang & - & - & 1 & 1 & - & - & - & - & - & - & - \\
\hline Henan & 1 & 1 & 3 & 1 & - & - & - & - & - & - & - \\
\hline Shaanxi & 1 & 2 & 2 & 1 & 1 & - & - & - & - & - & - \\
\hline Anhui & - & - & - & - & 2 & - & - & - & - & - & - \\
\hline Heilongjiang & 3 & 1 & 4 & 1 & 2 & - & - & - & - & - & - \\
\hline Hunan & - & - & - & 4 & 2 & - & & - & - & - & - \\
\hline Shanxi & 3 & 3 & 1 & - & - & 1 & - & - & - & - & - \\
\hline Guangdong & 2 & 2 & & 1 & 1 & 1 & & - & - & - & - \\
\hline Shandong & 2 & 3 & 1 & 2 & 1 & 1 & - & - & - & - & - \\
\hline Sichuan & 2 & 5 & 2 & 5 & 1 & 2 & - & - & - & - & - \\
\hline Hainan & - & - & - & - & - & - & 1 & - & - & - & - \\
\hline Jilin & 4 & 1 & 2 & - & 1 & - & 1 & - & - & - & - \\
\hline Jiangxi & 1 & 2 & 1 & 3 & 1 & - & - & 1 & - & - & - \\
\hline Liaoning & 3 & 2 & - & 1 & 1 & - & - & - & 1 & - & - \\
\hline Hebei & 4 & 2 & 1 & 1 & 1 & - & - & - & 1 & - & - \\
\hline Hubei & 1 & 1 & - & 2 & 7 & 2 & 2 & - & 1 & - & - \\
\hline Fujian & - & - & 1 & 2 & 2 & 1 & 1 & 1 & 1 & - & - \\
\hline Jiangsu & 3 & 1 & 1 & 7 & - & 2 & 1 & - & 1 & - & 1 \\
\hline North region & 9 & 5 & 2 & - & - & 1 & - & - & - & - & - \\
\hline Northeast region & 11 & 4 & 6 & 2 & 4 & - & 1 & - & 1 & - & - \\
\hline Huanghuai region & 6 & 6 & 6 & 10 & 3 & 2 & 1 & - & 2 & - & 1 \\
\hline South region & 11 & 13 & 10 & 20 & 16 & 7 & 4 & 2 & 2 & - & - \\
\hline
\end{tabular}

accessions were postulated to have no Rps genes with susceptible reactions to all isolates. Seven accessions (ZDD01169, ZDD02149, ZDD04429, ZDD07409, ZDD08018, ZDD17622, and ZDD18524) were postulated to have the Rps7 gene because they had the same reaction type (SSSSSSSSSSR) as the differential cultivar Harosoy, which carries Rps7. The accessions ZDD14783 and ZDD16675 from the Hunan and Guangdong provinces were postulated to have the Rps4 gene because their reaction type RSRRRSSSRSS was consistent with the differential cultivar L85-2352, which carries Rps4. The accession ZDD03741 from the Jiangsu province had the reaction type RRRRRRRRSSR
Table 4 Accessions with resistant reactions to between 8 to 11 isolates of Phytophthora sojae

\begin{tabular}{llll}
\hline Accessions & Reaction type $^{a}$ & Province & Ecological region \\
\hline ZDD06501 & RRRSRRRRSRS & Jiangxi & South \\
ZDD21485 & RRRRRRSSRSR & Fujian & South \\
ZDD00921 & RRRRRRSRRRS & Liaoning & North \\
ZDD06363 & RRRRRRRRSRS & Fujian & South \\
ZDD03741 & RRRRRRRRSSR & Jiangsu & Huanghuai \\
ZDD11581 & RRRRRRRRRSS & Hubei & South \\
ZDD18835 & RRRRRRRRRSS & Hebei & Huanghuai \\
ZDD03776 & RRRRRRRRRRR & Jiangsu & Huanghuai \\
\hline
\end{tabular}

${ }^{\mathrm{a}}$ The reaction type an accession occurred is a combination of reactions of the accession to P6497, HLJ08-17, P7063, AH, H15, HeN08-35, PNJ1, Pmg, Pm28, Pm31 and JS08-12 isolates

and was postulated to have a gene combination of Rps1c and Rps7. Accession ZDD16874 from the Hainan province had the reaction type RRRRRRRSSSS and was postulated to have gene combinations of $R p s 1 \mathrm{~b}$ with Rps1d/Rps2/Rps5/Rps6. The other 105 reaction types were not consistent with any single $R p s$ gene or twogene combinations. Based on these results, we postulated that more than two Rps genes or novel Rps genes were present in most resistant accessions.

\section{Linkage disequilibrium decay in the soybean mini core collection}

The soybean mini core collection was genotyped with 1,645 SNP markers. The physical distribution of SNPs was fairly uniform, with an average of $1.72 \mathrm{SNPs} / \mathrm{Mb}$ for the entire genome, and varied between a minimum of $0.80 \mathrm{SNPs} / \mathrm{Mb}$ on Gm01 and a maximum of 3.57 SNPs/ $\mathrm{Mb}$ on $\mathrm{Gm08}$ (Additional file 4). After excluding markers with $>15 \%$ missing data, a minor allele frequency $<0.05$ and heterozygosity $>0.15$, a total of 1,514 high quality SNPs were selected for association mapping.

The mean $r^{2}$ values for unlinked and linked SNP pairs were 0.01 and 0.03 . With increasing physical distance between loci, $r^{2}$ values declined rapidly. The average LD decay for all chromosomes was estimated at $544.01 \mathrm{~kb}$ at $r^{2}<0.04$ and described by the red curve in Fig. 4 .

\section{Population structure and relative kinship of the soybean mini core collection}

STRUCTURE 2.2 software [39] analysis indicated that the soybean mini core collection was divided into two main subgroups (Fig. 5a). The germplasm belonging to each subgroup had differences in geographical origin (Fig. 5b). Fifty-one accessions belonged to subgroup 1, among which one accession (ZDD19579) came from the SR, 13 accessions came from the HHR, 27 accessions came from the NR and 10 accessions came from the NER. Subgroup 2 was a large group that included 173 
Table 5 Gene postulations and reaction types of soybean accessions

\begin{tabular}{lll}
\hline Accession & Reaction type $^{\text {a }}$ & Gene postulation \\
\hline ZDD00294, ZDD00310, ZDD00638, ZDD00932, & SSSSSSSSSSS & \\
ZDD01402, ZDD01983, ZDD02096. ZDD02114, & \\
ZDD02134, ZDD02159, ZDD02315, ZDD02400, & \\
ZDD02626, ZDD02940, ZDD03533, ZDD03540, & \\
ZDD03733, ZDD06410, ZDD06822, ZDD06823, & \\
ZDD07370, ZDD07489, ZDD07623, ZDD08120, & \\
ZDD08228, ZDD08238, ZDD08251, ZDD08352, & \\
ZDD08472, ZDD08603, ZDD08728, ZDD08928, & \\
ZDD08986, ZDD09136, ZDD09279, ZDD10252, & \\
ZDD10270, ZDD11092, ZDD11159, ZDD11226, & \\
ZDD12407, ZDD12680, ZDD12908, ZDD12910, & \\
ZDD13666, ZDD14228, ZDD14920, ZDD16682, & \\
ZDD16743, ZDD17325, ZDD17375, ZDD17457, & \\
ZDD17574, ZDD18632, ZDD19464, ZDD20671 & SSSSSSSSSSR \\
ZDD01169, ZDD02149, ZDD04429, ZDD07409, & \\
ZDD08018, ZDD17622, ZDD18524 & RSRRRSSSRSS \\
ZDD14783, ZDD16675 & RRRRRRSSSSS \\
ZDD16874 & & Rps7 \\
ZDD03741 & RRRRRRRRSSR & Rps4 \\
\hline
\end{tabular}

${ }^{\mathrm{a}}$ The reaction type an accession occurred is a combination of reactions of the accession to P6497, HLJ08-17, P7063, AH, H15, HeN08-35, PNJ1, Pmg, Pm28, Pm31 and JS08-12 isolates

accessions, among which 99 accessions came from the SR, 35 accessions came from the HHR, 10 accessions came from the NR and 29 accessions came from the NER, which accounted for almost all of the germplasm from the SR, $73.0 \%$ from the HHR, $27.0 \%$ from the NR and $74.4 \%$ from the NER. According to the variation and the level of resistance in the four regions, subgroup 2 had the most resistance accessions and a higher resistance level.

Pairwise kinship was calculated among the soybean accessions. Approximately $67.2 \%$ of the pairwise kinship coefficients were $0.3-0.4$, and only $2.0 \%$ were larger than 0.5 , indicating weak relatedness among the soybean germplasm (Fig. 6).

\section{Association mapping and candidate genes for Phytophthora resistance}

We used a Naive model, a GLM model (Q) and a MLM model $(\mathrm{Q}+\mathrm{K})$ for association mapping (Additional file 5). A total of 82 marker-trait associations were detected with the Naive model, while 29 and 12 resistance associations were identified with the GLM and MLM models by applying a $P<10^{-3}$ threshold (Additional file 6). To improve the reliability of the results, we focused on associations supported by at least two models. Finally, fourteen marker-trait associations identified by at least two models were considered to have significant associations with $P$. sojae resistance (Table 6). Nine $(64.3 \%)$ of them were within or near the

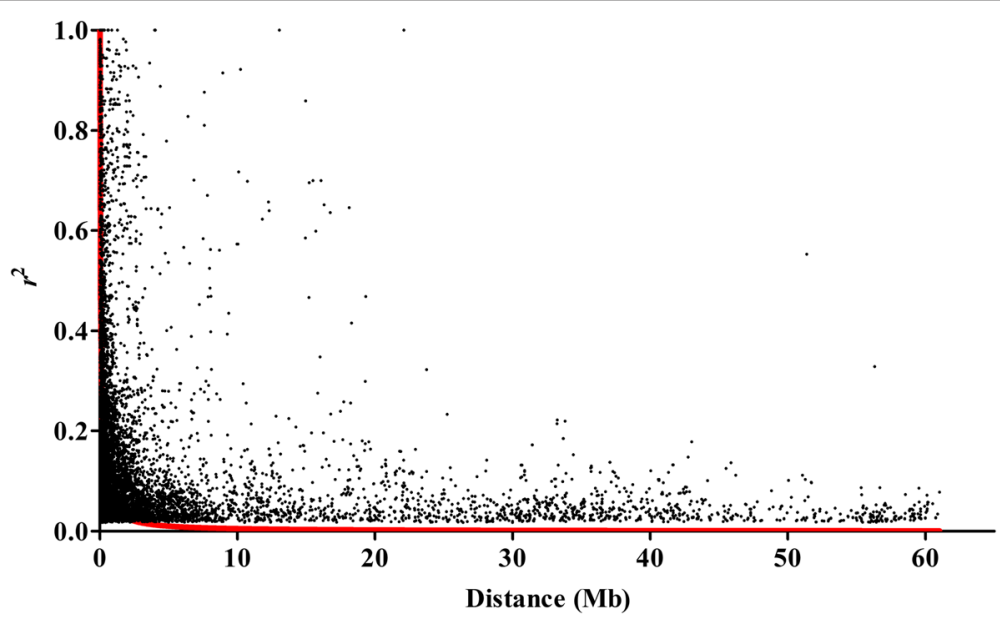

Fig. 4 Scatter plots and LD decay against physical distance among co-chromosome SNPS 

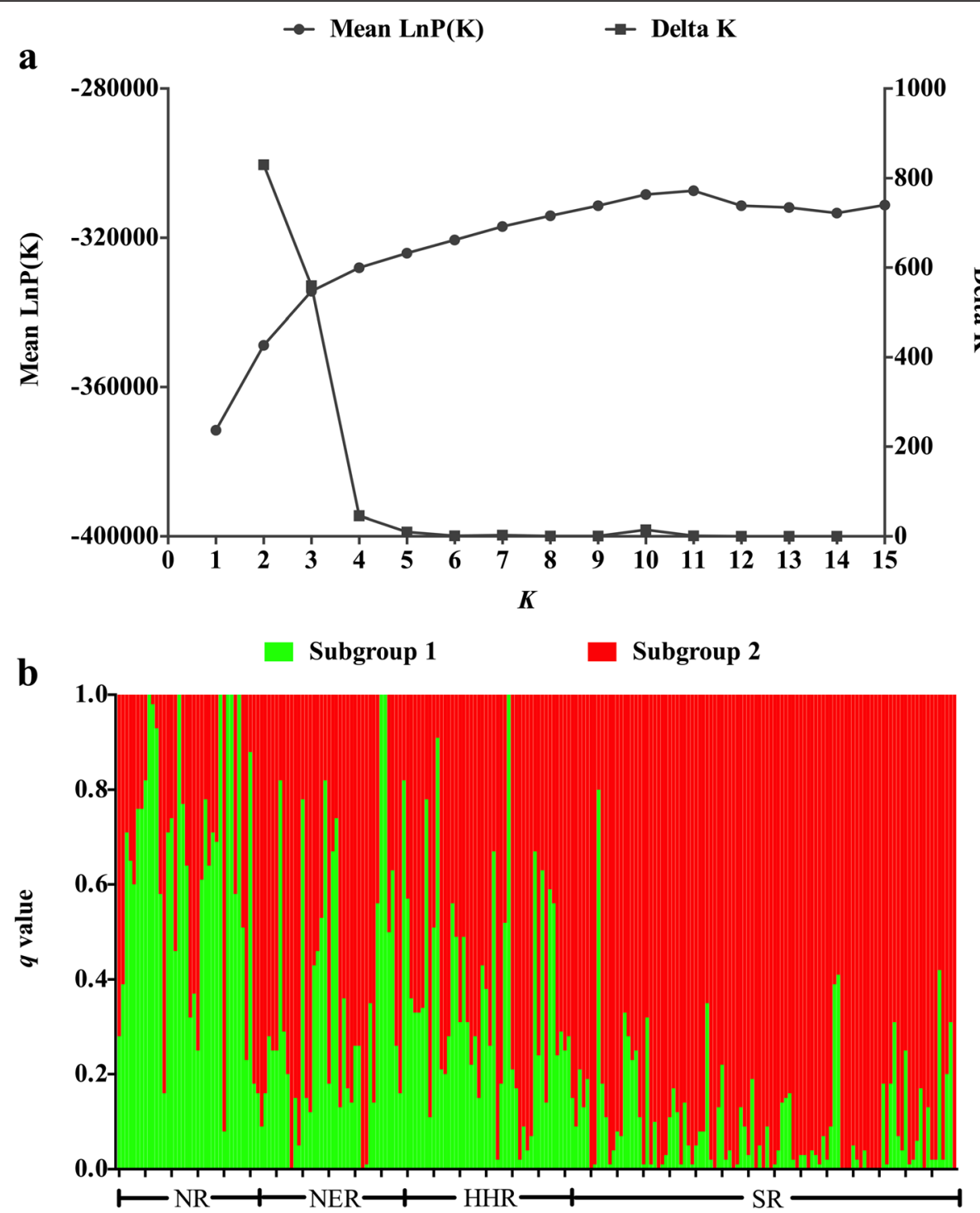

Fig. 5 Population structure of the soybean mini core collection. The $L n P(D)$ and Delta K values when $k$ from 1 to 15 shows in Fig (a). Fig (b) shows the $q$ value of soybean accessions belonged to two subgroups. The subgroup 1 shows in green color and subgroup 2 shows in red color. The vertical coordinate of each subgroup indicates the $q$ value for each individual, and the digits on the horizontal coordinate represent the origin region of soybean

genomic regions detected in previous studies on soybean disease resistance (http://www.soybase.org/), while five associations were newly associated with Phytophthora resistance.

The most significant association with resistance to the HLJ08-35 isolate was on Gm15. The resistance trait for the P7063 isolate had associations in the same region with two SCN-QTLs [43, 44], on Gm03 and Gm15, respectively. One resistance association of the H15 isolate was on Gm16, within a brown stem rot (BSR) resistance QTL [45] interval. For the HeN08-35 isolate, two significant associations were on $\mathrm{Gm} 16$ and Gm20, respectively. The resistance to the PNJ1 isolate showed associations with genome regions on Gm06 and Gm16, which were co-located with SCN-QTL [46] and PRR-QTL [47, 48]. For the Pmg isolate, one marker-trait association on Gm11 overlapped with a sclerotinia stem rot (SSR) resistance locus [49], and one on Gm16 in the same RpsUn2 interval [50] was identified. Two associations with resistance to the $\mathrm{Pm} 28$ isolate were located on $\mathrm{Gm} 03$ and Gm15 in the same regions of Rps1 [51] and PRR-QTL [52]. Resistance to the Pm31 isolate had two associations, on Gm04 and $\mathrm{Gm} 09$.

To shed light on the potential genes involved in resistance to $P$. sojae, 14 significantly associated SNP markers were selected to represent these marker-trait associations (Table 7). They resided in 12 annotated 


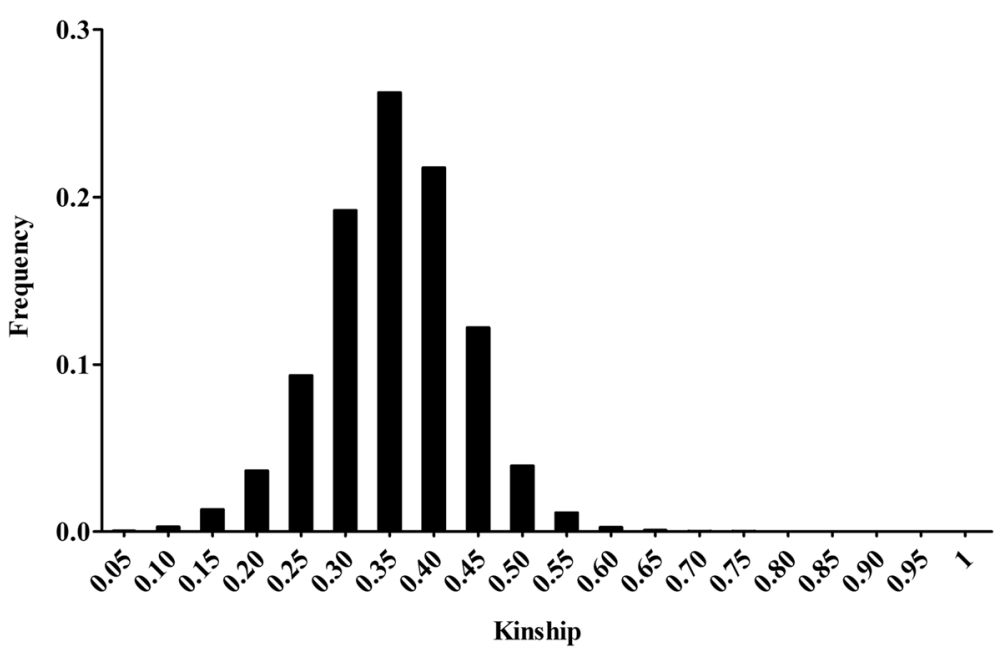

Fig. 6 Distribution of pairwise relative kinship estimates between mini core collection

genes, among which 10 SNPs were located in gene exons, and 2 SNPs were located in introns. The candidate genes encode a LEM3 (ligand-effect modulator 3) family/CDC50 family member protein, an ARF-related/ ADP-ribosylation factor gene, a predicted lipase class 3 gene, a thioredoxin gene, a DEAD/DEAH box helicase, an oxygenase, a serine/threonine protein kinase, an NPH3 family protein, a zinc finger protein, a lipid transport protein, an ankyrin repeat and a calmodulinbinding motif protein. This is the first time that these genes were reported to be associated with Phytophthora resistance.

\section{Discussion}

In this study, a systematic and effective analysis of Phytophthora resistance to various $P$. sojae isolates in the Chinese soybean mini core collection was performed. The mini core collection was extremely susceptible to the isolates from China and America (Table 1), with an average of $23.6 \%$ of accessions showing resistance to $P$. sojae isolates tested, which implied the urgency of soybean resistance breeding. A total of 168 (75\%) soybean accessions showed resistance to more than one $P$. sojae isolate, suggesting that abundant resistant resources exist. An overview of the resistance

Table 6 SNP markers identified in association mapping of P. sojae resistance

\begin{tabular}{|c|c|c|c|c|c|c|c|c|c|c|}
\hline \multirow[t]{2}{*}{ Isolate } & \multirow[t]{2}{*}{ SNP markers } & \multirow[t]{2}{*}{ Chr } & \multirow[t]{2}{*}{ Position } & \multicolumn{2}{|l|}{ Naive } & \multicolumn{2}{|l|}{ GLM } & \multicolumn{2}{|l|}{ MLM } & \multirow{2}{*}{$\begin{array}{l}\text { Co-located } \\
\text { trait }^{a}\end{array}$} \\
\hline & & & & $-\log _{10} P$ & $R^{2}(\%)$ & $-\log _{10} P$ & $R^{2}(\%)$ & $-\log _{10} P$ & $R^{2}(\%)$ & \\
\hline HLJ08-17 & Q-15-0369188 & 15 & 48863575 & 5.08 & 10.35 & 4.12 & 8.35 & 2.85 & 6.27 & New \\
\hline P7063 & Q-03-0266907 & 3 & 36634361 & 5.18 & 10.43 & 3.14 & 5.53 & 1.82 & 3.23 & SCN [43] \\
\hline P7063 & Q-15-0128012 & 15 & 15532390 & 5.87 & 13.67 & 3.60 & 7.91 & 2.00 & 5.05 & SCN [44] \\
\hline $\mathrm{H} 15$ & Q-16-0268535 & 16 & 33793393 & 2.33 & 5.02 & 3.14 & 6.48 & 3.03 & 6.87 & $\mathrm{BSR}[45]$ \\
\hline HeN08-35 & BARC-014467-01559 & 16 & 3962328 & 3.58 & 7.48 & 3.37 & 6.93 & 3.17 & 7.00 & New \\
\hline HeN08-35 & BARC-013645-01207 & 20 & 46624541 & 3.34 & 6.84 & 3.72 & 7.46 & 3.21 & 6.95 & New \\
\hline PNJ1 & BARC-014527-01571 & 6 & 644565 & 3.45 & 7.28 & 3.44 & 7.17 & 3.44 & 7.65 & SCN [46] \\
\hline PNJ1 & Map-3031 & 16 & 15093996 & 3.04 & 5.02 & 3.35 & 5.54 & 3.01 & 5.18 & $\operatorname{PRR}[47,48]$ \\
\hline Pmg & Map-1995 & 11 & 7904934 & 2.84 & 4.72 & 3.61 & 6.16 & 3.45 & 6.19 & SSR [49] \\
\hline Pmg & BARC-042413-08254 & 16 & 35175092 & 4.64 & 9.90 & 3.97 & 8.45 & 3.68 & 8.33 & RpsUN2 [50] \\
\hline $\operatorname{Pm} 28$ & Q-03-0059953 & 3 & 5147782 & 2.06 & 3.36 & 3.19 & 5.54 & 3.08 & 5.69 & Rps1 [51] \\
\hline Pm28 & BARC-039153-07459 & 15 & 831324 & 5.00 & 10.67 & 4.79 & 10.14 & 3.68 & 8.60 & PRR [52] \\
\hline Pm31 & Map-0715 & 4 & 46749591 & 1.09 & 2.35 & 3.64 & 7.42 & 3.09 & 6.86 & New \\
\hline Pm31 & Map-1630 & 9 & 3157784 & 4.37 & 9.09 & 3.41 & 6.98 & 3.08 & 6.84 & New \\
\hline
\end{tabular}

${ }^{\mathrm{a}}$ The SNP co-located in one of the loci intervals as reported previously 
Table 7 Candidate genes related to $P$. sojae resistance

\begin{tabular}{lllll}
\hline SNP marker & Nucleotide & Location & Gene & Annotation $^{\text {a }}$ \\
\hline Q-15-0369188 & A/G & Exon & Glyma15g41680 & LEM3 (ligand-effect modulator 3) family/CDC50-related \\
Q-15-0128012 & A/G & Exon & Glyma03g28660 & ARF-related/ADP-ribosylation factor \\
Q-16-0268535 & A/G & Exon & Glyma15g18620 & unknown \\
BARC-014467-01559 & A/T & Exon & Glyma16g30140 & Predicted lipase class 3 gene \\
BARC-013645-01207 & G/T & Exon & Glyma16g04700 & Thioredoxin \\
BARC-014527-01571 & C/T & Exon & Glyma20g39240 & DEAD/DEAH box helicase \\
Map-3031 & A/G & Intron & Glyma06g01080 & 2OG-Fe (II) oxygenase superfamily \\
Map-1995 & Intron & Glyma16g14080 & Serine/threonine protein kinase \\
BARC-042413-08254 & A/G & Exon & Glyma11g11100 & Phototropic-responsive NPH3 family protein \\
Q-03-0059953 & A/G & Exon & Glyma16g31930 & Zinc finger domain \\
BARC-039153-07459 & A/C & Exon & Glyma03g04960 & Lipid transport protein \\
Map-0715 & Intron & Glyma15g01370 & unknown \\
Map-1630 & C/G & Exon & Glyma04g40800 & Serine/threonine protein kinase \\
\hline
\end{tabular}

${ }^{a}$ Annotation description provided by the Soybean Genome Project, DoE Joint Genome Institute (http://www.soybase.org/)

spectrum of the mini core collection to $11 \mathrm{P}$. sojae isolates was given. Twenty-four (10.7 \%) accessions were resistant to more than five isolates, and eight accessions were notably resistant to $8-11$ isolates (Table 4). In conjunction with the previous screening of Chinese resistant germplasm [20, 22, 53], the results provide an excellent database for selection of resistant cultivars and potential breeding materials.

Most accessions resistant to multiple isolates were concentrated in the South and Huanghuai regions, especially in the Jiangsu, Hubei, Sichuan and Fujian provinces, similar to previous results $[19,20,22,53$, 54]. The South and Huanghuai regions have abundant precipitation (1000-1500 mm/year) and high temperatures (annual accumulated temperature is $4000-8000{ }^{\circ} \mathrm{C}$ ) $[55,56]$, which can promote the growth $P$. sojae isolates [9]. The high disease pressure in these regions may be the major factor promoting the variety of resistant resources found therein. The PNJ1 and JS0812 isolates from the SR and the HeN08-35 isolate from the HHR showed strong virulence to 6-13 Rps genes, which coincided with the high level of resistance displayed by soybean in those regions. Conversely, soybean accessions in the NR and NER tend to be more susceptible, resulting in the need to broaden the genetic base and breed resistant cultivars. The results of our study combined with an investigation of $P$. sojae pathotypes, especially the dominant pathotypes from each region of China, may provide a reasonable guide for planting cultivars with different resistance genes, which would be an effective means of PRR disease control.

The various reaction types of soybean accessions indicated that accessions may carry different Rps genes. The greater frequency of resistance reactions in the mini core collection than in the differential cultivars implied that the collection may carry more or novel resistance genes. According to the gene postulation, only 67 accessions were predicted to contain Rps1b, Rps1c, Rps4 or Rps7. The number of postulated accessions was not as high as in previous studies $[20,22]$, perhaps due to the complex virulence effects of the isolates we used, which made the probability of a soybean accession having the same reaction type as one differential cultivar only $224 / 2^{13}$. The other 157 resistance accessions may have multiple or novel resistance genes. Developing bi-parental populations of these accessions and fine mapping resistance genes may be one way of confirming the results of the gene postulation.

The observed phenotypic variations implied abundant genetic diversity in the mini core collection. When genotyped with 1,645 SNP markers, the mini core collection showed abundant genetic diversity, weak population structure and familial relatedness. We used an association mapping approach to identify genomic loci associated with variations in resistance phenotypes. A total of 14 significant resistance associations were identified, among which five were newly associated with Phytophthora resistance, and four were located in known Rps gene/QTL regions. Five other associations were located in the same chromosomal regions of resistance QTLs of other diseases, such as SCN and BSR (Table 6), implying that these regions may contain pleiotropic genes or different resistance genes clustered together. Research on these loci may enable understanding of the genetics of resistance to multiple pathogens. The highest $P$-value of significantly associated SNPs was $8.38 \times 10^{-6}$, which is not as high as that of other studies 
$[28,57]$. This may be due to the small number of SNP markers that we used, which may reduce the degree of association. To date, only the Rps $1 \mathrm{k}$ gene has been cloned [58, 59], although the mechanism underlying Phytophthora resistance is still unclear. The resistanceassociated loci may be helpful in marker-assisted selection and in understanding the mechanism that mediates resistance.

We chose genes where the most significantly associated SNP markers were located as candidate genes for associations. Glyma15g41680 is a member of the LEM3 (ligand-effect modulator 3) family/CDC50 protein family, and it may be required for phospholipid translocation across the plasma membrane [60]. Glyma03g28660 is an ADP-ribosylation factor gene. ADP-ribosylation factor 1 (RARF1) induced pathogenesis-related gene expression and pathogen resistance when it was overexpressed in tobacco plants [61], and it acted as a positive regulator of cell death [62]. Glyma16g30140 is a predicted lipase class 3 gene that may have essential functions in plant defence or priming. Ectopic expression of AtPAD4 possessing a lipase 3 motif broadened resistance to SCN and root-knot nematode (RKN) diseases in the soybean [63]. Glyma16g04700 encodes a thioredoxin protein. Two transcript variants of the Pi-ta protein, which coupled the original NBS-LRR domain with a $\mathrm{C}$-terminal thioredoxin domain, showed the highest level of expression in comparison to other transcript variants in rice [64]. Glyma20g39240 is a DEAD/DEAH box helicase, which may take part in splicing the RNA precursor [65] and in transcription initiation [66]. Glyma06g01080 belongs to the 2OG-Fe (II) oxygenase superfamily and may catalyse the formation of plant hormones, such as ethylene and gibberellins. In Arabidopsis, the DMR6 gene, which has the same domain, is defence-associated and required for susceptibility to downy mildew [67]. Glyma16g14080 and Glyma04g40800 encode a serine/threonine protein kinase, which not only has signal transduction activity but also inhibits the release of spores and the germination of the germ tube in Phytophthora infestans [68]. Glyma11g11100 encodes an NPH3 family protein, which activates signal transduction and regulates auxin signalling during plant growth [69, 70]. Glyma16g31930 contains a zinc finger domain, which has been shown to negatively regulate transcription [71, 72]. Many NBS-LRR domain genes contain zinc finger domains [73], and some have been reported to play a role in resistance to PRR [74]. Glyma03g04960 encodes a lipid transport protein (LTP); lipid signals are essential for the activation of plant defence responses. Many studies have shown that over-expression of LTPs in plants can enhance their resistance to pathogens [75-77], possibly through inhibition of germination of their spores [78]. Glyma09g04310 has an ankyrin repeat and a calmodulin-binding motif. The ankyrin repeat participates in the regulation of transcription [79]; for example, the AKP2 gene in Arabidopsis is a negative regulator of $P R-1$ (pathogen-related protein 1) expression [80]. Calmodulin-binding proteins can detect external stimuli and regulate systemic acquired resistance [81, 82]. Over-expression of GmCaM4 in the soybean resulted in enhanced resistance to three pathogens through increased expression of pathogenesis-related (PR) genes [83]. In future studies, the functions of these genes in the resistance process will be examined.

Some studies have inferred that some Rps genes contain NBS-LRR domains $[13,58,59]$. In our study, no such NBS-LRR-domain gene was found among the candidates, which may due to the complex mechanism of soybean resistance. This situation has been found in other disease studies. For instance, soybean resistance to SCN through the Rgh1 locus is conferred through copy number variation, but the Glyma18g02680.1 gene in the Rhg1 locus, which encodes an LRR-kinase, does not contribute to $\mathrm{SCN}$ resistance $[84,85]$.

\section{Conclusions}

The information presented in this study will be of great value to plant breeders in their efforts to develop PRR resistance breeding programs in the soybean. The results revealed the urgency of resistance breeding and provided excellent resources for breeding materials, especially the soybean from the South and Huanghuai regions, which showed high levels of resistance. An association mapping of Phytophthora resistance identified fourteen significant marker-trait associations, nine of which were located within known PRR or other disease resistance loci; five of these associations were previously unknown in Phytophthora resistance. In the future, candidate genes related to resistance will be functionally identified to understand the resistance mechanism in the soybean.

\section{Additional files}

\footnotetext{
Additional file 1: The geographic distribution of soybean mini core collection in China. The soybean accessions are divided into four ecological regions: the North region (NR), the Northeast region (NER), the Huanghuai region (HHR) and the South region (SR). (PDF $286 \mathrm{~kb}$ )

Additional file 2: Information of SNP markers used in association mapping study. (XLS $175 \mathrm{~kb}$ )

Additional file 3: Percentage of $P$. sojae isolates with a susceptible interaction with Rps genes. (PDF $65 \mathrm{~kb}$ )

Additional file 4: The numbers and distribution of SNPS on each chromosome. (PDF $44 \mathrm{~kb}$ )

Additional file 5: Genome-wide association study of soybean $P$. sojae resistance in three models. (PDF $2447 \mathrm{~kb}$ )

Additional file 6: SNP markers associated with $P$. sojae resistance traits in three models. (PDF $76 \mathrm{~kb}$ )
} 


\section{Acknowledgements}

We thank Dr. Jianbo He and Dr. Guangnan Xing for providing bioinformatics technical assistance and Dr. Qiang Yan and graduate student Ammara Tahir for critical reviewing of the manuscript. This work was supported by Special Fund for Agro-scientific Research in the Public Interest (201303018, 201203026), Modern Agro-industry Technology Research System of China (CARS-004-PS10), Jiangsu Province Science and Technology Support Project (BE2013350) and National Natural Science Foundation of China (31301340, 31301343).

\section{Availability of data and material}

The data sets supporting the results of this article are included within the article and its additional files.

\section{Authors' contributions}

All authors have read and approved the manuscript. HX and LQ conceived and coordinated the work. NG and JMZ conducted planting soybean materials. YHL and YFL developed molecular markers. JH, JTS, GJH and HPZ conducted phenotyping experiments. JH and XZ conducted association mapping experiments. JH wrote the manuscript.

\section{Competing interests}

The authors declare that they have no competing interests.

\section{Consent for publication}

Not applicable.

\section{Ethics approval and consent to participate}

Not applicable.

\section{Received: 16 February 2016 Accepted: 25 May 2016}

Published online: 18 June 2016

\section{References}

1. Wrather JA, Anderson TR, Arsyad DM, Gai J, Ploper LD, Porta-Puglia A, et al. Soybean disease loss estimates for the top 10 soybean producing countries in 1994. Plant Dis. 1997:81(1):107-10.

2. Dorrance $A E_{\text {, Jia } H}$, Abney TS. Evaluation of soybean differentials for their interaction with Phytophthora sojae. Plant Health Prog. 2004. doi:10.1094/php-2004-0309-01-rs.

3. Dorrance AE, Berry SA, Anderson TR, Meharg C. Isolation, storage, pathotype characterization, and evaluation of resistance for Phytophthora sojae in soybean. Plant Health Prog. 2008. doi:10.1094/PHP-2008-0118-01-DG.

4. Shen CY, Su YC. Discovery and preliminary studies of Phytophthora Megasperma on soybean in China. Acta Phytopathologica Sinica (in Chinese). 1991;21:289

5. Su YC, Shen CY. The discovery and biological characteristics studies of Phytophthora Megasperma f. sp.glycinea on soybean in China. Acta Phytopathologica Sinica (in Chinese). 1993:28:341-7.

6. Zhu ZD, Wang HB, Wang XM, Chang RZ, WU XF. Distribution and virulence diversity of Phytophthora sojae in China. Agr Sci China. 2004;3(2):116-23.

7. Schmitthenner AF. Phytophthora rot of soybean. In: Hartman GL, Sinclair JB, Rupe JC, editors. Compendium of soybean diseases. St. Paul, MN 55121 USA: The American Phytopathological Society Press; 1999. p. 39-42.

8. Bernard RL, Smith PE, Kaufmann MJ, Schmitthenner AF. Inheritance of resistance to Phytophthora root and stem rot in the soybean. Agron J. 1957;49(7):391.

9. Demirbas A, Rector BG, Lohnes DG, Fioritto RJ, Graef GL, Cregan PB, et al. Simple sequence repeat markers linked to the soybean Rps genes for Phytophthora resistance. Crop Sci. 2001;41(4):1220-7.

10. Weng C, Yu K, Anderson TR, Poysa V. Mapping genes conferring resistance to Phytophthora root rot of soybean, Rpsia and Rps7. J Hered. 2001;92(5): 442-6.

11. Sugimoto T, Yoshida S, Watanabe K, Ano M, Kanto T, Maekawa K, et al. Identification of SSR markers linked to the Phytophthora resistance gene Rps 1-d in soybean. Plant Breeding. 2008;127(2):154-9.

12. Wu XL, Zhang BQ, Sun S, Zhao JM, Yang F, Guo N, et al. Identification, genetic analysis and mapping of resistance to Phytophthora sojae of Pm28 in soybean. Agricultural Sciences China. 2011;10(10):1506-11.

13. Sun S, Wu XL, Zhao JM, Wang YC, Tang QH, Yu DY, et al. Characterization and mapping of RpsYu25, a novel resistance gene to Phytophthora sojae. Plant Breeding. 2011;130(2):139-43.
14. Sun J, Li L, Zhao J, Huang J, Yan Q, Xing H, et al. Genetic analysis and fine mapping of RpsJS, a novel resistance gene to Phytophthora sojae in soybean [Glycine max (L.) Merr]. Theor Appl Genet. 2014;127(4):913-9.

15. Flor $\mathrm{HH}$. Current status of the gene-for-gene concept. Annu Rev Phytopathol. 1971;9:275-96.

16. Tyler BM. Phytophthora sojae: root rot pathogen of soybean and model oomycete. Mol Plant Pathol. 2007;8(1):1-8.

17. Jones JD, Dang JL. The plant immune system. Nature. 2006;444:323-9.

18. Schmitthenner AF. Problems and progress in control of Phytophthora root rot of soybean. Plant Disease. 1985;69(4):362-8.

19. Lohnes DG, Nickell CD, Schmitthenner AF. Origin of soybean alleles for Phytophthora resistance in China. Crop Sci. 1996;36(6):1689-92.

20. Kyle DE, Nickell CD, Nelson RL, Pedersen WL. Response of soybean accessions from provinces in southern China to Phytophthora sojae. Plant Dis. 1998:82(5):555-9.

21. Tang QH, Cui LK, Li DL, Dai TT, Yin WX, Dong SM, et al. Resistance evaluation of soybean germplasm from huanghuai valley to Phytophthora root rot. China Agriculture Science (in Chinese). 2010;43(11):2246-52.

22. Zhang J, Sun S, Wang G, Duan C, Wang X, Wu X, et al. Characterization of Phytophthora resistance in soybean cultivars/lines bred in Henan province. Euphytica. 2013;196(3):375-84.

23. Qiu LJ, Li YH, Guan RX, Liu ZX, Wang LX. Establishment, representative testing and research progress of soybean core collection and mini core collection. Acta Agronomica Sinica (in Chinese). 2009;35(4):571-9.

24. Qiu LJ, Xing LL, Guo Y, Wang J, Jackson SA, Chang RZ. A platform for soybean molecular breeding: the utilization of core collections for food security. Plant Mol Biol. 2013;83(1):41-50.

25. Sun J, Guo N, Lei J, Li LH, Hu GJ, Xing H. Association mapping for partial resistance to Phytophthora sojae in soybean (Glycine max (L.) Merr.). J Genet. 2014;93(2):355-63.

26. Gupta PK, Rustgi S, Kulwal PL. Linkage disequilibrium and association studies in higher plants: present status and future prospects. Plant Mol Biol. 2005;57(4):461-85

27. Korte A, Farlow A. The advantages and limitations of trait analysis with GWAS: a review. Plant Methods. 2013;9:29.

28. Atwell S, Huang YS, Vilhjalmsson BJ, Willems G, Horton M, Li Y, et al. Genome-wide association study of 107 phenotypes in Arabidopsis thaliana inbred lines. Nature. 2010;465:627-31.

29. Appels R, Barrero R, Bellgard M. Advances in biotechnology and informatics to link variation in the genome to phenotypes in plants and animals. Funct Integr Genomics. 2013;13(1):1-9.

30. Iquira E, Humira S, Francois B. Association mapping of QTLs for sclerotinia stem rot resistance in a collection of soybean plant introductions using a genotyping by sequencing (GBS) approach. BMC Plant Biol. 2015;15(1):5.

31. Zhao X, Han Y, Li Y, Liu D, Sun M, Zhao Y, et al. Loci and candidate gene identification for resistance to Sclerotinia sclerotiorum in soybean (Glycine max L. Merr.) via association and linkage maps. Plant J. 2015;82(2):245-55.

32. Wen Z, Tan R, Yuan J, Bales C, Du W, Zhang S, et al. Genome-wide association mapping of quantitative resistance to sudden death syndrome in soybean. BMC Genomics. 2014:15:809.

33. Schmitthenner AF, Bhat RG. Useful methods for studying Phytophthora in the laboratory. Special Circular - Ohio Agricultural Research and Development Center. 1994. p. 143.

34. Li YH, Zhao SC, Ma JX, Li D, Yan L, Li J, et al. Molecular footprints of domestication and improvement in soybean revealed by whole genome re-sequencing. BMC Genomics. 2013;14:589-490.

35. Liu K, Muse SV. PowerMarker: an integrated analysis environment for genetic marker analysis. Bioinformatics. 2005;21(9):2128-9.

36. Bradbury PJ, Zhang Z, Kroon DE, Casstevens TM, Ramdoss Y, Buckler ES. TASSEL: software for association mapping of complex traits in diverse samples. Bioinformatics. 2007;23(19):2633-5.

37. Sved J. Linkage disequilibrium and homozygosity of chromosome segments in finite populations. Theor Pop Biol. 1971:2:125-41.

38. Mather KA, Caicedo AL, Polato NR, Olsen KM, McCouch S, Purugganan MD. The extent of linkage disequilibrium in rice (Oryza sativa L.). Genetics. 2007;177(4):2223-32.

39. Pritchard JK, Stephens M, Donnelly P. Inference of population structure using multilocus genotype data. Genetics. 2000;155(2):945-59.

40. Li YH, Li W, Zhang C, Yang L, Chang RZ, Gaut BS, et al. Genetic diversity in domesticated soybean (Glycine max) and its wild progenitor (Glycine soja) 
for simple sequence repeat and single-nucleotide polymorphism loci. New Phytol. 2010;188(1):242-53.

41. Remington DL, Thornsberry JM, Matsuoka Y, Wilson LM, Whitt SR, Doebley J, et al. Structure of linkage disequilibrium and phenotypic associations in the maize genome. P Natl Acad Sci USA. 2001;98(20):11479-84.

42. Anderson AD, Weir BS. A maximum-likelihood method for the estimation of pairwise relatedness in structured populations. Genetics. 2008; 176(1):421-40.

43. Guo B, Sleper DA, Nguyen HT, Arelli PR, Shannon JG. Quantitative trait loci underlying resistance to three soybean cyst nematode populations in soybean PI 404198A. Crop Sci. 2006;46(1):224-33.

44. Guo B, Sleper DA, Arelli PR, Shannon JG, Nguyen HT. Identification of QTLS associated with resistance to soybean cyst nematode races 2, 3 and 5 in soybean PI 90763. Theor Appl Genet. 2005;111(5):965-71.

45. Patzoldt ME, Carlson SR, Diers BW. Characterization of resistance to brown stem rot of soybean in five accessions from central China. Crop Sci. 2005;45(3):1092-5.

46. Wang D, Arelli PR, Shoemaker RC, Diers BW. Loci underlying resistance to Race 3 of soybean cyst nematode in Glycine soja plant introduction 468916. Theor Appl Genet. 2001;103(4):561-6.

47. Weng CR, Yu KF, Anderson TR, Poysa V. A quantitative trait locus influencing tolerance to Phytophthora root rot in the soybean cultivar 'Conrad'. Euphytica. 2007:158(1-2):81-6.

48. Tucker DM, Saghai Maroof MA, Mideros S, Skoneczka JA, Nabati DA, Buss GR, et al. Mapping quantitative trait loci for partial resistance to Phytophthora sojae in a soybean interspecific cross. Crop Sci. 2010:50:628-35.

49. Arahana VS, Graef GL, Specht JE, Steadman JR, Eskridge KM. Identification of QTLs for resistance to Sclerotinia sclerotiorum in soybean. Crop Sci. 2001;41(1):180-8.

50. Lin F, Zhao M, Ping J, Johnson A, Zhang B, Abney TS, et al. Molecular mapping of two genes conferring resistance to Phytophthora sojae in a soybean landrace PI 567139B. Theor Appl Genet. 2013;126(8):2177-85.

51. Diers BW, Mansur L, Imsande J, Shoemaker RC. Mapping Phytophthora resistance loci in soybean with restriction-fragment-length-polymorphism markers. Crop Sci. 1992;32(2):377-83.

52. Wu X, Zhou B, Zhao J, Guo N, Zhang B, Yang F, et al. Identification of quantitative trait loci for partial resistance to Phytophthora sojae in soybean. Plant Breeding. 2011;130(2):144-9.

53. Xia CJ, Zhang JQ, Wang XM WUXF, Liu ZX, Zhu ZD. Analyses of resistance genes to Phytophthora root rot in soybean germplasm. Chinese J Oil Crop Sciences (in Chinese). 2011;4(33):396-401.

54. Chen XL, Zhu ZD, Wang XM, Xiao YN, Wu XF. Postulation of Phytophthora resistance genes in soybean cultivars or lines. Scientia Agricultura Sinica (in Chinese). 2008:41(4):1227-34.

55. Hou W, Chen Y, Ying L, Wang Y, Wang Z, Zhu X, et al. Climatic characteristics over China in 2014. Meteorological Monthly (in Chinese). 2015;41(4):480-8.

56. Zhang $\mathrm{H}$, Zhang Y. Prelimiary disscussion on the response of active accumulated temperature of China to climate warming. Acta Geographica Sinica (in Chinese). 1994;49(1):27-36.

57. Sonah H, O'Donoughue L, Cober E, Rajcan I, Belzile F. Identification of loci governing eight agronomic traits using a GBS-GWAS approach and validation by QTL mapping in soya bean. Plant Biotechnol J. 2015;13(2):211-21.

58. Bhattacharyya MK, Narayanan NN, Gao H, Santra DK, Salimath SS, Kasuga T, et al. Identification of a large cluster of coiled coil-nucleotide binding site-leucine rich repeat-type genes from the Rps 1 region containing Phytophthora resistance genes in soybean. Theor Appl Genet. 2005; 111(1):75-86.

59. Gao H, Bhattacharyya MK. The soybean-Phytophthora resistance locus Rps 1-k encompasses coiled coil-nucleotide binding-leucine rich repeat-like genes and repetitive sequences. BMC Plant Biol. 2008:8:29.

60. Kato U, Emoto K, Fredriksson C, Nakamura H, Ohta A, Kobayashi T, et al. A novel membrane protein, Ros $3 p$, is required for phospholipid translocation across the plasma membrane in Saccharomyces cerevisiae. J Biol Chem. 2002;277(40):37855-62.

61. Lee WY, Hong JK, Kim CY, Chun HJ, Park HC, Kim JC, Yun D-J, Chung WS, Lee S-H, Lee SY, Cho MJ, Lim CO. Over-expressed rice ADP-ribosylation factor 1 (RARF1) induces pathogenesis-related genes and pathogen resistance in tobacco plants. Physiol Plantarum. 2003;119:573-81.
62. Coemans B, Takahashi Y, Berberich T, Ito A, Kanzaki H, Matsumura H, Saitoh H, Tsuda S, Kamoun S, Sagi L, Swennen R, Terauchi R. High-throughput in planta expression screening identifies an ADP-ribosylation factor (ARFI) involved in non-host resistance and $\mathrm{R}$ gene-mediated resistance. Mol Plant Pathol. 2008;9(1):25-36

63. Youssef RM, MacDonald MH, Brewer EP, Bauchan GR, Kim KH, Matthews BF. Ectopic expression of AtPAD4 broadens resistance of soybean to soybean cyst and root-knot nematodes. BMC Plant Biol. 2013;13:67.

64. Costanzo S, Jia Y. Alternatively spliced transcripts of $P$ i-ta blast resistance gene in Oryza sativa. Plant Sci. 2009;177(5):468-78.

65. Linder P. Dead-box proteins: a family affair-active and passive players in RNP-remodeling. Nucleic Acids Res. 2006;34(15):4168-80.

66. Sonenberg N. Cap-binding proteins of eukaryotic messenger RNA: functions in initiation and control of translation. Prog Nucleic Acid Res Mol Biol. 1988:35:173-207.

67. Van Damme M, Huibers RP, Elberse J, Guido VDA. Arabidopsis DMR6 encodes a putative 20G-Fe(II) oxygenase that is defense-associated but required for susceptibility to downy mildew. Plant J. 2008;54:785-93.

68. Judelson $\mathrm{HS}$, Roberts $\mathrm{S}$. Novel protein kinase induced during sporangial cleavage in the oomycete Phytophthora infestans. Eukaryot Cell. 2002;1:687-95.

69. Cheng Y, Qin G, Dai X, Zhao Y. NPY1, a BTB-NPH3-like protein, plays a critical role in auxin-regulated organogenesis in Arabidopsis. Proc Natl Acad Sci U S A. 2007:104(47):18825-29.

70. Sakai T, Wada T, Ishiguro S, Okada K. RPT2 A signal transducer of the phototropic response in Arabidopsis. Plant Cell. 2000;12:225-36.

71. Fox AH, Liew C, Holmes M, Kowalski K, Mackay J, Crossley M. Transcriptional cofactors of the FOG family interact with GATA proteins by means of multiple zinc fingers. Embo J. 1999;18:2812-22.

72. Miller J, McLachlan AD, Klug A. Repetitive zinc-binding domains in the protein transcription factor IIIA from Xenopus oocytes. EMBO J. 1985;4(6):1609-14.

73. Gupta SK, Rai AK, Kanwar SS, Sharma TR. Comparative analysis of zinc finger proteins involved in plant disease resistance. PLoS One. 2012;7:e42578.

74. Wang $Y L$, Dou DL, Wang $X L$, Li AN, Sheng $Y T$, Hua $C L$, et al. The PsCZF1 gene encoding a $\mathrm{C} 2 \mathrm{H} 2$ zinc finger protein is required for growth, development and pathogenesis in Phytophthora sojae. Microb Pathog. 2009;47:78-86.

75. Blein JP, Coutos-Thévenot P, Marion D, Ponchet M. From elicitins to lipidtransfer proteins: a new insight in cell signalling involved in plant defence mechanisms. Trends Plant Sci. 2002;7:293-6.

76. Sarowar S, Kim YJ, Kim KD, Hwang BK, Ok SH, Shin JS. Overexpression of lipid transfer protein (LTP) genes enhances resistance to plant pathogens and LTP functions in long-distance systemic signaling in tobacco. Plant Cell Rep. 2009;28:419-27.

77. Bae H, Roberts DP, Lim HS, Strem MD, Park SC, Ryu CM, et al. Endophytic Trichoderma isolates from tropical environments delay disease onset and induce resistance against Phytophthora capsici in hot pepper using multiple mechanisms. Mol Plant Microbe Interact. 2011;24:336-51.

78. Ge X, Chen J, Li N, Lin Y, Sun C, Cao K. Resistance function of rice lipid transfer protein LTP110. J Biochem Mol Biol. 2003:36:603-7.

79. Mosavi LK, Minor DL, Peng ZY. Consensus-derived structural determinants of the ankyrin repeat motif. Proc Natl Acad Sci U S A. 2002;99:16029-34.

80. Yan J, Wang J, Zhang $\mathrm{H}$. An ankyrin repeat-containing protein plays a role in both disease resistance and antioxidation metabolism. Plant J. 2002;29:193-202.

81. Truman W, Zabala MT, Grant M. Type III effectors orchestrate a complex interplay between transcriptional networks to modify basal defence responses during pathogenesis and resistance. Plant J. 2006;46:14-33.

82. Dodd AN, Kudla J, Sanders D. The language of calcium signaling. Annu Rev Plant Biol. 2010;61:593-620.

83. Rao SS, El-Habbak MH, Havens WM, Singh A, Zheng D, Vaughn L, et al. Overexpression of GmCaM4 in soybean enhances resistance to pathogens and tolerance to salt stress. Mol Plant Pathol. 2014;15:145-60.

84. Melito S, Heuberger A, Cook D, Diers B, MacGuidwin A, Bent A. A nematode demographics assay in transgenic roots reveals no significant impacts of the Rhg1 locus LRR-Kinase on soybean cyst nematode resistance. BMC Plant Biol. 2010;10:1-14.

85. Cook DE, Bayless AM, Wang K, Guo X, Song Q, Jiang J, et al. Distinct copy number, coding sequence, and locus methylation patterns underlie Rhg1mediated soybean resistance to soybean cyst nematode. J Plant Physiol. 2014;165:630-47. 